\title{
Building constructions modelling problems in modern cae-systems
}

\author{
Vadim Alpatov ${ }^{1, *}$ \\ ${ }^{1}$ Samara State Technical University, 194 Molodogvardeyskaya St., Samara, Russia
}

\begin{abstract}
This article is about choosing building structure analysis model question. Construction analysis model type choice affects result of counting. Result accuracy and reliability depends on analysis scheme choice. Using modern computers, there is a lot of alternative abilities of creation construction analysis model. This article is made to understand these analysis models features and their influence on result. An example of counting beam in six independent CAD systems is shown. Engineering simulation and design software, which base on finite elements method, were chosen for analysis. These counting models differ from each other only by geometrical scheme. Beam geometry modeling is performed using beam elements, shell elements and solid elements. The comparison of beam calculation results with its beam, shell and solid elements analysis scheme modelling was performed. The analysis of single factor (geometric scheme) influence on the results of beam calculation is shown. It was defined, that the choice of calculation complex does not affect the calculation result, if the geometrical counting models are completely identical. It was defined, that in case creating construction with various types finite elements there are differences in the calculation results. Difference in calculation results, using different geometrical models, is seen in using the same complex and in comparison of different complexes. It was defined, that difference in calculating internal forces and moments in beam for different geometrical models can be more than $10 \%$.
\end{abstract}

\section{First Section}

Today we see an increase in the number of buildings and structures created on individual and exclusive projects. Individual projects are developed for private cottages, for apartment buildings, for public buildings, for urban planning in general. This variety of architectural forms increases the complexity and labour intensity of projects [1-6]. The individual nature of projects leads to more complex structures of structural frames of buildings. Modern construction projects are so complex that it is not possible to cope with all the problems that arise at the stage of their implementation without computers.

Developers of CAD, CAM, CAE applications always creating new versions of program complexes, which are able to solve building tasks. There is a concurrence between developers of program complexes for designing buildings. Every developer adds new functions to standard ones. These functions widen program complex abilities, making it more universal.

*Corresponding author: avu75@mail.ru 
An integration between program complexes developers occurs. Converters and functional abilities of information exchange between program complexes of different developers are being created. Great variety of program complexes is good, but users do not always understand the difference between them. More, user usually isn't able to define which program product he needs. It is especially seen in choosing CAE programs, which means programs allowing to make calculations on structural analysis of constructions. For solution this problems, developers create a lot of seminars, conferences, hold consultations, and create trial versions of their programs.

CAE program complexes allow to solve different tasks of building mechanics [7-9]. Of course, they have borders of applicability, but developers permanently widen them, that's why, especially young users, think that they are infinite. Specialists know that construction calculation results would be greatly influenced by chosen analysis model. Reliability of a real construction is defined by reliability, accuracy and certainty of its calculation. The stage of choosing the analysis model of construction is not regulated in any way and is strictly the prerogative of designer. Thus, final reliability of a building or a structure depends on designer competence. Experience shows, that new programs are easier understood by young people. Young specialists, who don't have deep theoretical knowledge in building mechanics and «blinded» by abilities of calculation complexes, usually make mistakes in analysis model choice. Even experienced projectors, taking into account increasing difficulty of projecting structures, are not always able to decide which analysis model to choose. Analysis model is always simplified idealized model of a real construction. Real construction properties simplifying in its analysis model can made to a greater or lesser extent. Attempts of analysis model maximal simplifying lead to loss of information and estrangement in performance of model from a physical prototype. Attempts to take into account all of «the smallest parts» leads to excessive complication of a task and can become a reason of «hidden» mistakes appearing, and the impossibility of getting the result for complicated models. Of course, assumed analysis model accordance to physical prototype reliability is a real experiment. But real experimental researches are much more complicated and expensive in comparison to digital researches. That is why digital research of construction analysis model choice on final result of its calculation is an actual task.

\section{Second Section}

Not only projectors and program developers are worried by building structures calculations, but supervisory authorities too. That is why one of new requirements for project documentation for buildings and constructions, passing independent examination in Russia - is submitting calculations of a construction made in art least two calculating complexes. This is a necessary, but insufficient step to improve building objects reliability. Important role in calculation reliability has construction analysis model choice. One construction can be modelled in a calculation complex using different methods, for example, beam elements, shell elements and solid elements or combined model. It is necessary to make calculations on several alternative models or to justify choice of one model, to improve reliability of building objects. It is especially important for complicated schemes, which have no serial developments and analogues [10-13].

Further in the text an example of counting beam in seven independent CAD systems is shown. The following CAD systems were used for analysis: Lira, SCAD, VA2000, CosmosM, STAAD, AnalysisGroup, CosmosWorks. As an illustration of analysis model choice importance in making calculation on a computer, results of construction calculation - statically determinate metallic beam with uniformly distributed load are presents. Beam has $3000 \mathrm{~mm}$ length, a double-T section, load value 7,5 KN/m, physical characteristics of 
steel C245 [14]. Beam is simply supported and statically determinate. Beam calculations were made in these variants:

1. using a beam elements model in program complex Lira;

2. using a beam elements model in program complex SCAD;

3. using a beam elements model in program complex STAAD;

4. using a beam elements model in program complex AnalysisGroup;

5. using a beam elements model in program complex VA2000;

6. using a beam elements model in program complex CosmosWorks;

7.using a shell elements model in program complex Lira;

8. using a shell elements model in program complex SCAD;

9. using a shell elements model in program complex STAAD;

10. using a shell elements model in program complex VA2000;

11. using a shell elements model in program complex CosmosWorks;

12. using a solid elements model in program complex Lira;

13. using a solid elements model in program complex SCAD;

14. using a solid elements model in program complex STAAD;

15. using a solid elements model in program complex VA2000;

16. using a solid elements model in program complex CosmosWorks.

The information about calculating construction is submitted on Figure 1.
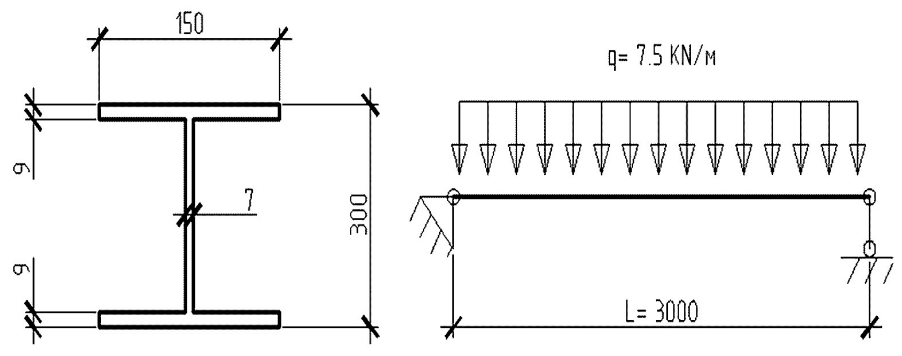

Fig. 1. Calculating construction.

Some analysis models and results of their calculations using different CAE-systems are submitted on Figures 2-10. Calculation results comparison was made by maximal internal moment and maximal internal shear force. In conclusions rating of differences between calculation results, counted in percent's is submitted. Values of internal forces in beam rod model were used as a beginning value in counting percent's divergence. 


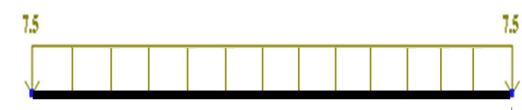

a.

$3 \mathrm{~m}$

c.

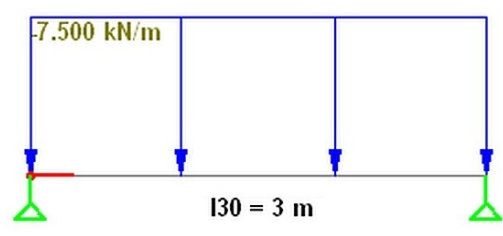

d.

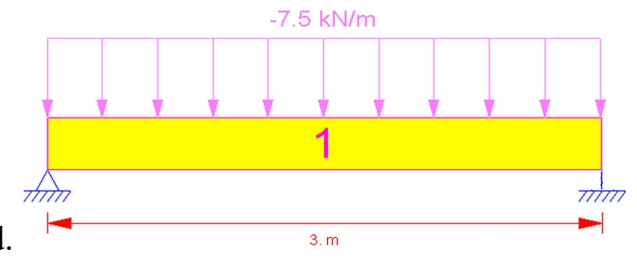

f.

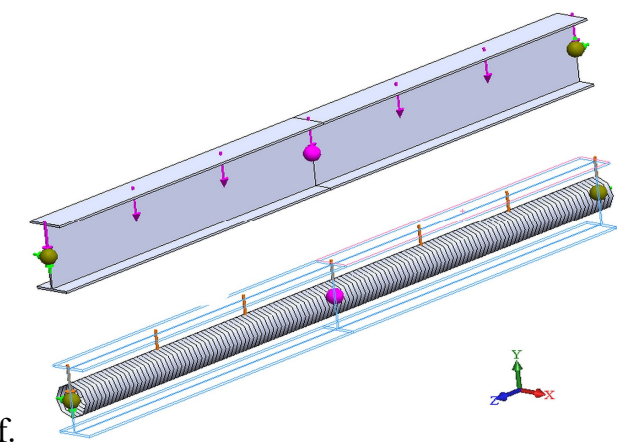

Fig. 2. Beam elements analysis model in CAE-systems: a. Lira; b. SCAD; c. STAAD; d. AnalysisGroup; e. VA2000; f. CosmosWorks.
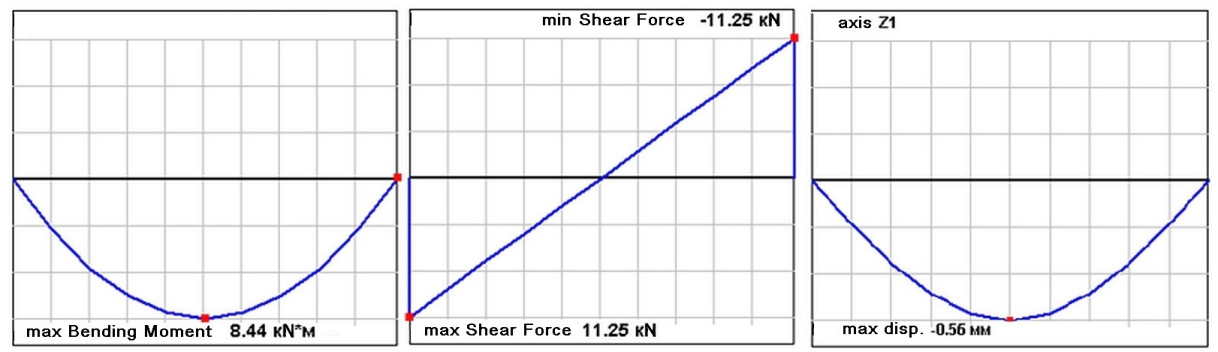

Fig. 3. Calculations results of beam elements analysis model of SCAD calculation complex. 

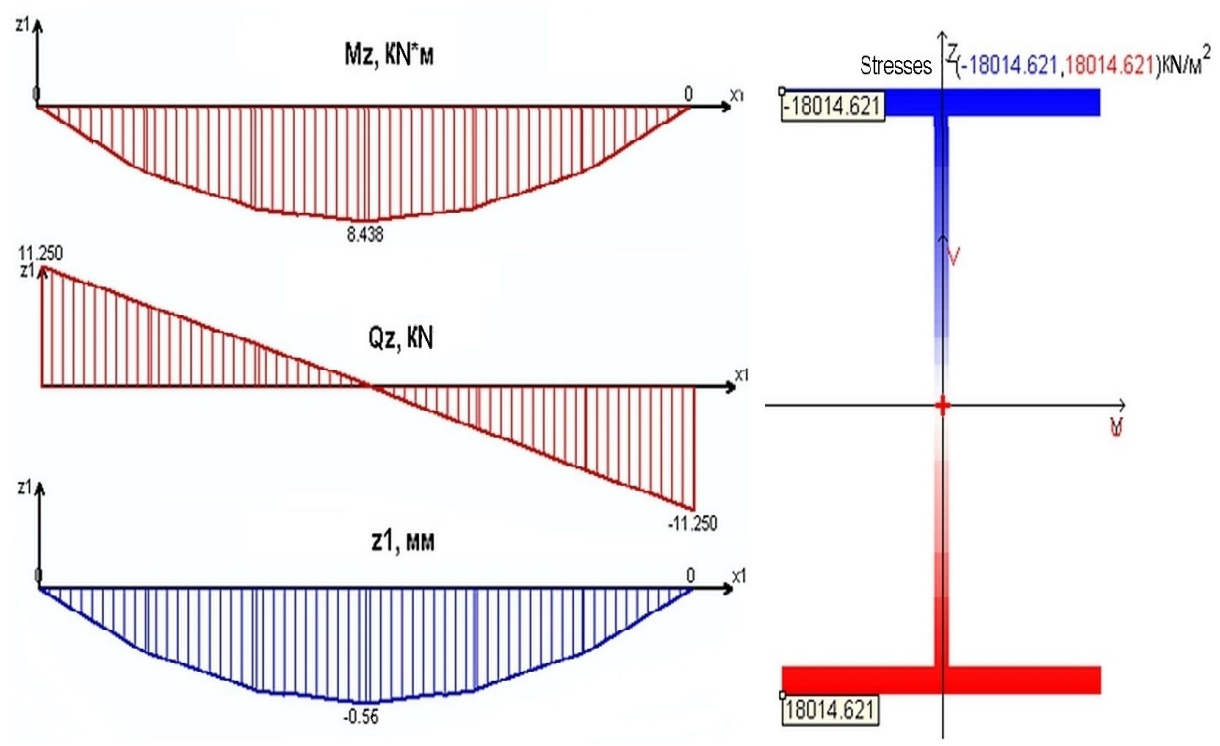

Fig. 4. Calculations results of beam elements analysis model of Lira calculation complex.
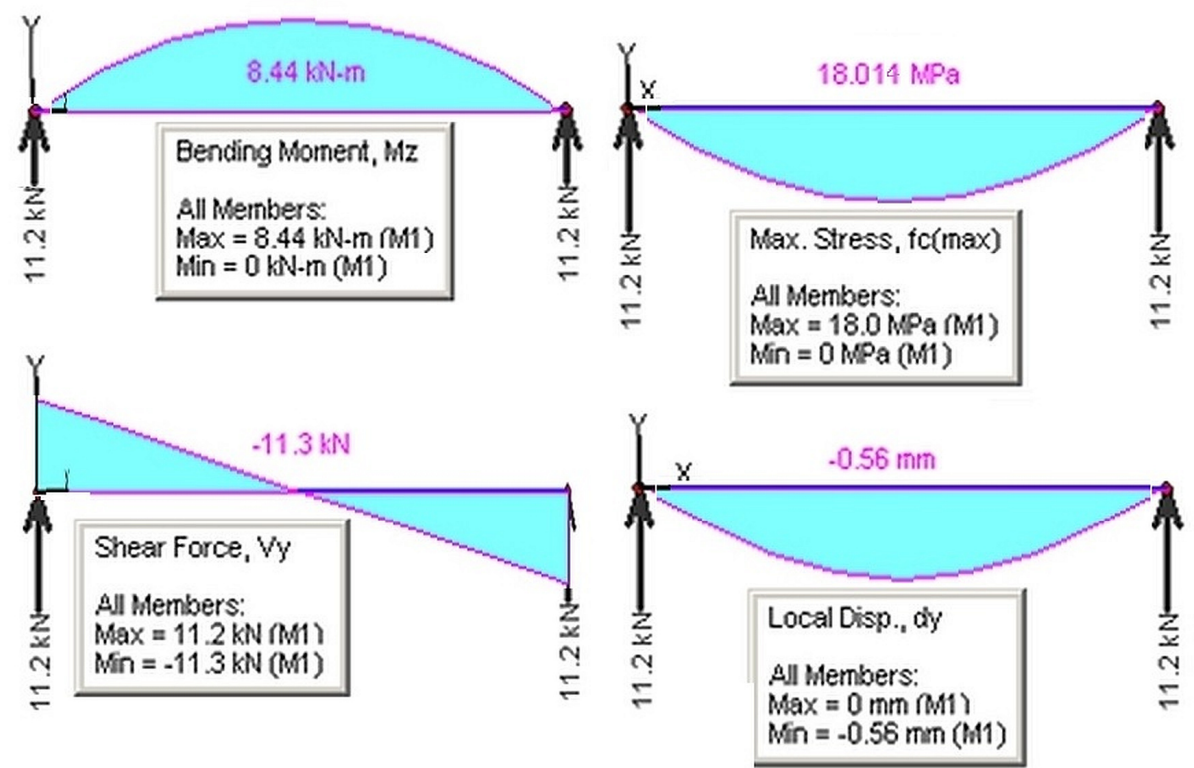

Fig. 5. Calculations results of beam elements analysis model of VA2000 calculation complex. 

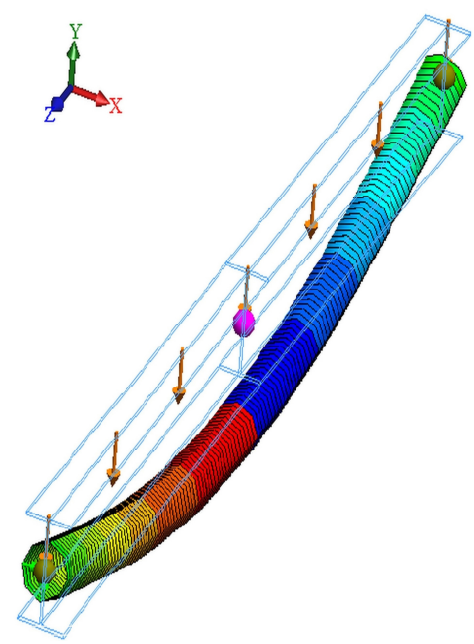

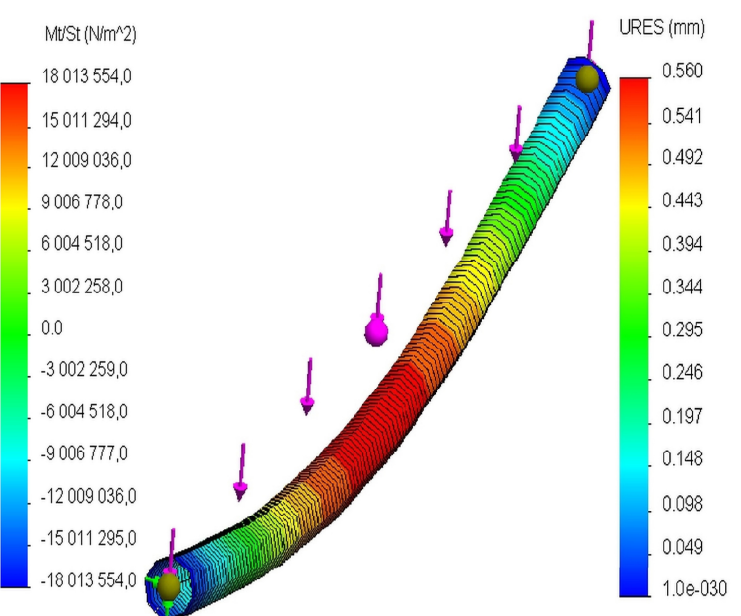

Fig. 6. Calculations results of beam elements analysis model of CosmosWorks calculation complex.

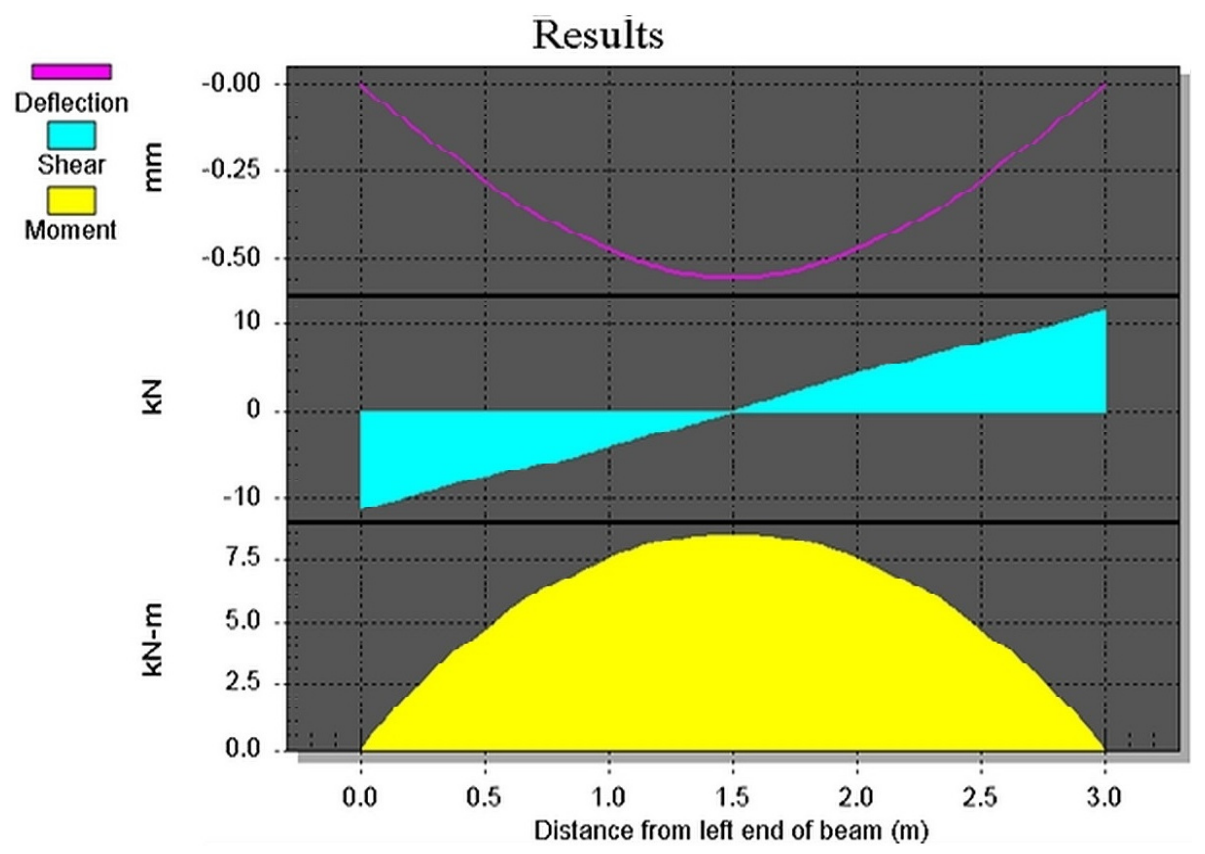

Fig. 7. Calculations results of a rod model of AnalysisGroup calculation complex. 


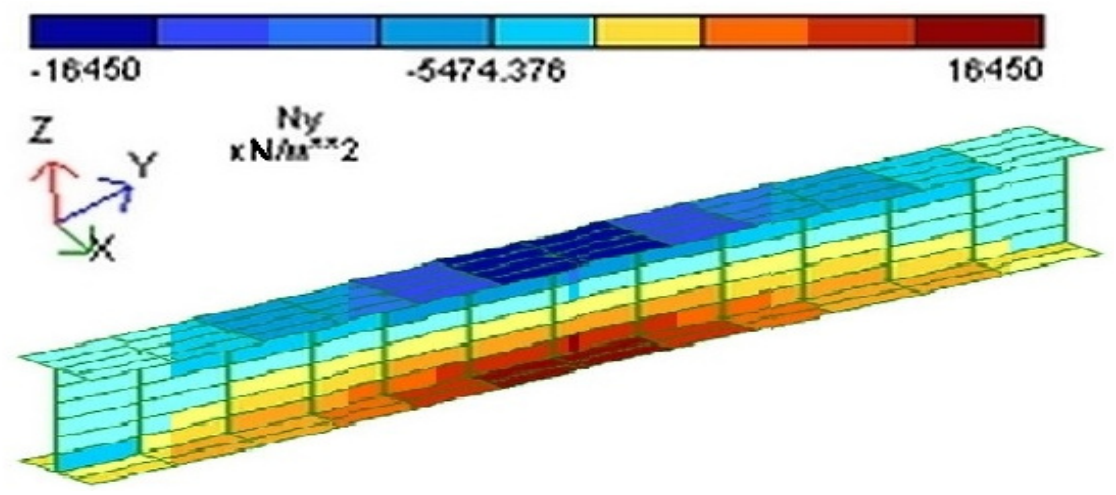

Fig. 8. Calculations results of shell elements analysis model of Lira calculation complex.

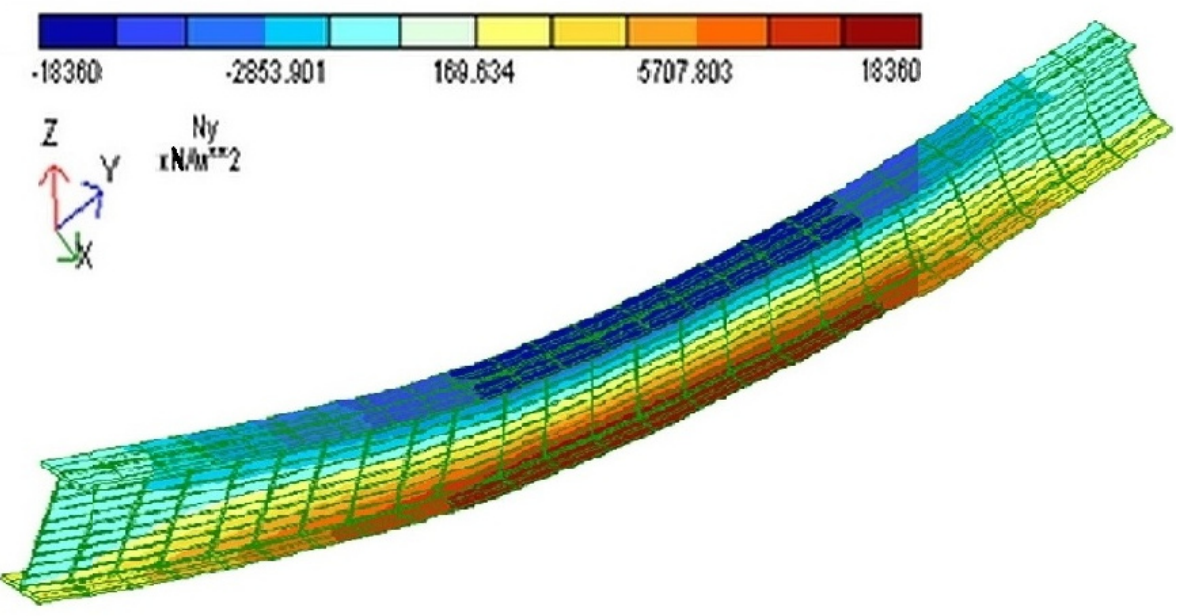

Fig. 9. Calculations results solid elements analysis model of Lira calculation complex.
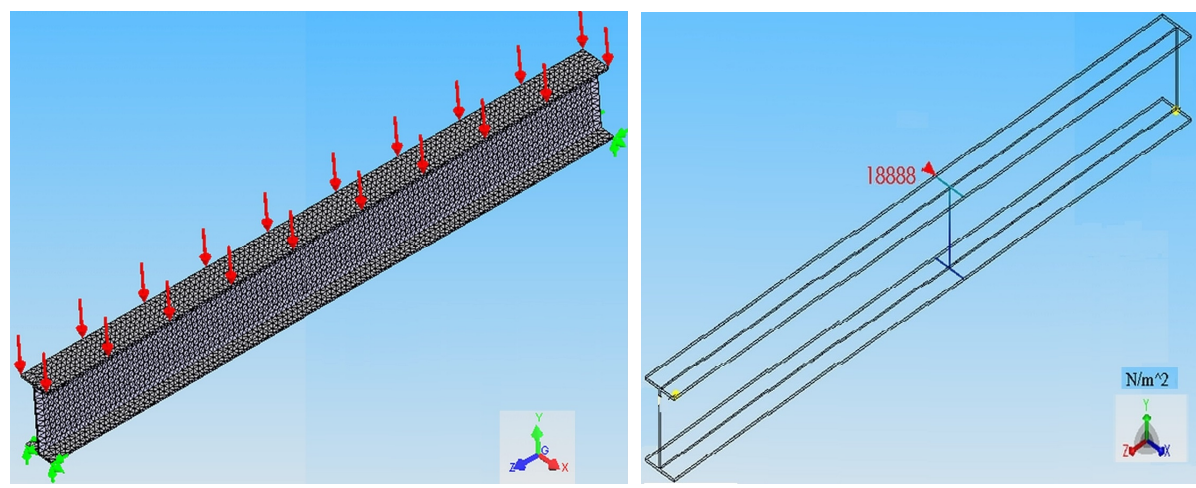

Fig. 10. Solid elements analysis model of CosmosWorks calculation complex. 
Table 1. Results of calculations.

\begin{tabular}{|c|c|c|c|c|c|c|c|c|}
\hline \multirow[t]{3}{*}{ CAE-system } & \multicolumn{8}{|c|}{ Type of analysis model } \\
\hline & \multicolumn{4}{|c|}{ Beam elements model } & \multicolumn{2}{|c|}{$\begin{array}{l}\text { Shell elements } \\
\text { model }\end{array}$} & \multicolumn{2}{|c|}{$\begin{array}{l}\text { Solid elements } \\
\text { model }\end{array}$} \\
\hline & $\begin{array}{c}\text { Q, } \\
\mathrm{KN}\end{array}$ & $\begin{array}{c}\mathrm{M}, \\
\mathrm{KN} \cdot \mathrm{m}\end{array}$ & $\begin{array}{c}\text { Disp., } \\
\text { mm }\end{array}$ & $\begin{array}{c}\mathrm{Ny}, \\
\mathrm{KN} / \mathrm{m} 2\end{array}$ & $\begin{array}{c}\text { Disp., } \\
\text { mm }\end{array}$ & $\begin{array}{c}\mathrm{Ny}, \\
\mathrm{KN} / \mathrm{m} 2\end{array}$ & $\begin{array}{c}\text { Disp., } \\
\text { mm }\end{array}$ & $\begin{array}{c}\mathrm{Ny}, \\
\mathrm{KN} / \mathrm{m} 2\end{array}$ \\
\hline Lira & 11.25 & 8.438 & 0.56 & 18014 & 0.554 & 16298 & 0.680 & 18360 \\
\hline SCAD & 11.25 & 8.44 & 0.56 & 18014 & 0.565 & 16450 & 0.703 & 18543 \\
\hline STAAD & 11.25 & 8.44 & 0.56 & 18014 & 0.565 & 16505 & 0.745 & 18675 \\
\hline AnalysisGroup & 11.3 & 8.45 & 0.56 & 18014 & - & - & - & - \\
\hline VA2000 & 11.3 & 8.44 & 0.56 & 18014 & 0.566 & 15370 & 0.737 & 17555 \\
\hline CosmosWorks & 11.25 & 8.437 & 0.56 & 18013 & 0.604 & 17004 & 0.778 & 18888 \\
\hline
\end{tabular}

Table 2. Calculation results depending on the types of analysis models.

\begin{tabular}{|l|l|l|l|l|}
\hline \multirow{2}{*}{ CAE-system } & \multicolumn{4}{|l|}{ Relative calculation error, \% } \\
\cline { 2 - 5 } & $\begin{array}{l}\text { Parameter to } \\
\text { compare }\end{array}$ & \multicolumn{4}{l|}{ Type of analysis model } \\
\cline { 2 - 5 } & & Beam* & Shell & Solid \\
\hline Lira & Disp. & 0 & 1.07 & 21.4 \\
\hline & Ny & 0 & 9.53 & 1.92 \\
\hline SCAD & Disp. & 0 & 0.89 & 25.5 \\
\hline & Ny & 0 & 8.68 & 2.94 \\
\hline STAAD & Disp. & 0 & 0.89 & 33.03 \\
\hline & Ny & 0 & 8.38 & 3.67 \\
\hline VA2000 & Disp. & 0 & 1.07 & 31.61 \\
\hline & Ny & 0 & 14.68 & 2.55 \\
\hline CosmosWorks & Disp. & 0 & 7.86 & 38.93 \\
\hline & Ny & 0 & 5.6 & 4.86 \\
\hline
\end{tabular}

" Comparison of calculation results depending on the types of analysis models is carried out in relation to the Beam elements model.

Table 3. Comparison of calculation results obtained between various CAD systems.

\begin{tabular}{|l|l|l|l|l|l|l|}
\hline \multirow{3}{*}{ CAE-system } & \multicolumn{6}{l|}{ Relative calculation error, \% } \\
\cline { 2 - 8 } & \multicolumn{2}{|l|}{ Beam elements model } & \multicolumn{2}{l|}{ Shell elements model } & \multicolumn{2}{l|}{ Solid elements model } \\
\cline { 2 - 8 } & Disp. & Ny & Disp. & Ny & Disp. & Ny \\
\hline Lira & 0 & 0 & 1.95 & 1.3 & 8.7 & 1.7 \\
\hline SCAD & 0 & 0 & 0 & 0.33 & 5.64 & 0.7 \\
\hline STAAD & 0 & 0 & 0 & 0 & 0 & 0 \\
\hline AnalysisGroup & 0 & 0 & - & - & - & - \\
\hline VA2000 & 0 & 0 & 0.2 & 6.9 & 1.07 & 5.99 \\
\hline CosmosWorks & 0 & 0,006 & 6.9 & 3.0 & 4.43 & 1.14 \\
\hline
\end{tabular}

* Comparison of CAE-systems is carried out in relation to the STAAD complex.

\section{Summary}

Conclusions, made from results of a calculation: 
1.it was defined, that choice of a CAE-system doesn't affect the result, if construction analysis models are the same. There is completely no difference in results in different CAEsystems;

2.there is a difference in calculation results, got for solid element and beam elements models. Difference, using one CAE-system, is shown. The difference can reach 38.93\%;

3.there is a difference in calculation results, got for shell element and beam elements models. Difference, using one CAE-system, is shown. Difference is not more than $14.68 \%$;

4.there is a difference in the calculation results obtained for shell elements models in various CAD-systems. The difference can reach $6.9 \%$.

5.there is a difference in the calculation results obtained for solid elements models in various CAD-systems. The difference can reach $8.7 \%$.

\section{References}

1. E. Generalova, V. Generalov, CTBUH Journal 4, 36-42 (2018).

2. E. Generalova, V. Generalov, EMMFT-2018: International Scientific Conference Energy Management of Municipal Facilities and Sustainable Energy Technologies, 768777 (2018).

3. V. Generalov, E. Generalova, Vestnik of SSUACE. Town Planning Archit. 4(21), 2329 (2015).

4. V. Generalov, E. Generalova, Urban Constr. Archit. 2(23), 85-90 (2016).

5. E. Generalova, V. Generalov, CTBUH J. (IV), 40-45 (2014).

6. V. Murgul, N. Vatin, E. Aronova, Appl. Mech. Mater. 680, 486-493 (2014).

7. V. Alpatov, M. Balzannikov, IOP Conf. Ser.: Mater. Sci. Eng. 456, 012011 (2018).

8. V. Alpatov, A. Lukin, et al, IOP Conf. Ser.: Mater. Sci. Eng. 456, 012010 (2018).

9. V. Alpatov, IOP Conf. Series: Materials Science and Engineering 463, 032103 (2018).

10. V. Shirokov, Izvestiya MGSU 9, 32-40 (2013).

11. T. Kaytukov, A. Belostosky, P. Akimov, V. Sidorov, IOP Conference Series: Materials Science and Engineering 456, 012072 (2018).

12. O. Hattab, M. Chaari, et al, Journal of Sound and Vibration 440, 239-25 (2019).

13. V. Travush, A. Martirosyan, G. Kashevarova, Procedia Engineering 153, 773-780 (2016).

14. L. V. Pushkareva, O. A. Galochkina, O. L. Bezgacheva, Espacios 40(4), 22 (2019) 